\title{
Recurrent hyponatremia in woman with undiagnosed postpartum pituitary insufficiency
}

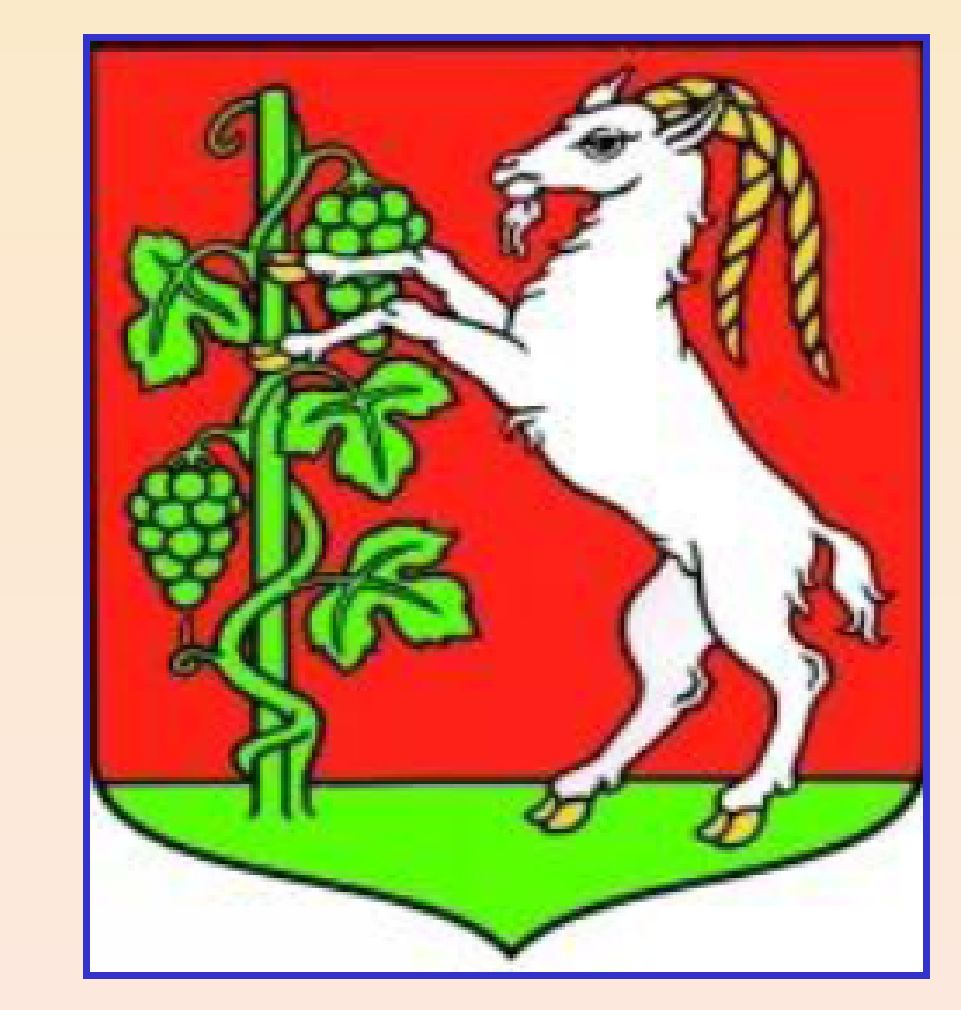

\author{
Maria Kurowska, Joanna Malicka, Agnieszka Zwolak, Jerzy S. Tarach \\ Department of Endocrinology, Medical University, Lublin, Poland
}

Introduction. Sheehan syndrome is a common cause of hypopituitarismus in women. The main reason of its diagnostic delay is high frequency of atypical signs. Hyponatremia occurs in $33-69 \%$ of women with postpartum pituitary necrosis.

The aim of the study was to present a patient in whom recurrent hyponatremia was one of the dominant symptoms of postpartum deficiency of anterior pituitary hormones.

Case report. 55-year-old woman with a diagnosis of Sheehan syndrome established 19 years after the last labour complicated by massive bleeding due to uterine atonia. The first symptoms of pituitary insufficiency were the lack of lactation and secondary amenorrhea. In addition, the patient complained of weakness, fatigue, psycho-motor retardation, depressed mood, dizziness, hypotension including orthostatic hypotension, flushing, loss of appetite, abdominal pain, recurrent episodes of nausea and vomiting, weight loss. She observed dry skin, loss of pubic and axillary hair, loss of eyelashes and eyebrows, and recurrent infections of the urogenital system. Over the last few years she was hospitalized for recurrent hyponatremia ( $\mathrm{Na}$ 115-125 mmol/l) many times.

Imaging studies. Ultrasound examination showed the $8.5 \mathrm{ml}$ thyroid gland with normal echogenicity. MRI revealed partial empty sella syndrome with small $(7 \times 3 \mathrm{~mm})$, symmetric pituitary and normal morphology of the signal.
The hormonal measurements were:

\begin{tabular}{|c|c|}
\hline Laboratory studies & Results \\
\hline ACTH level & \\
\hline [n: 7.2-63.6] & $32.5 \mathrm{pg} / \mathrm{ml}$ \\
\hline
\end{tabular}

Diurnal cortisol rhythm $\quad 2.6----1.3 \mu \mathrm{g} / \mathrm{dl}$

Daily cortisol excretion

[n: 55.5-286.0]

$6 \mu \mathrm{g}$

$<3.0 \mu \mathrm{g} / \mathrm{dl}$

[n: 25.9-460.0]

PRL

[n: 8.0-20.3]

$3.5 \mathrm{ng} / \mathrm{ml}$

LH

[n: 5.9-54.0]

$1.5 \mathrm{mIU} / \mathrm{ml}$

FSH

[n: 3.0-116.3]

$5.03 \mathrm{mlU} / \mathrm{ml}$

$\begin{array}{cc}\text { GH [n: } 0.1-5.0] & <0.1 \mathrm{ng} / \mathrm{ml} \\ \text { IGF-1 [n:50-184] } & 10 \mu \mathrm{m} / \mathrm{ml}\end{array}$

\begin{tabular}{c|l}
\hline Thyroid hormones & FT4 $=6.6 \mathrm{pmol} / \mathrm{I}$ \\
\hline FT4 [n: $12-22]$ & FT3 $=1.1 \mathrm{pmol} / \mathrm{I}$ \\
\hline FT3[n: $3-7]$ & TSH $=2.36 \mathrm{mIU} / \mathrm{I}$
\end{tabular}

Conclusion. Recurrent hyponatremia in the patient after a pathological labor may be one of the symptoms indicating the pituitary insufficiency. 